\title{
Toward Innovative Integrated Approaches for the Conservation of Mammals
}

\author{
Rafael Dias Loyola ${ }^{1, *}$, Eduardo Eizirik²,3, Ricardo Bonfim Machado ${ }^{4}$, \\ Ludmilla Moura de Souza Aguiar ${ }^{4}$, Daniel Brito ${ }^{1} \&$ Carlos Eduardo de Viveiros Grelle ${ }^{5}$
}

\author{
${ }^{1}$ Departamento de Ecologia, Instituto de Ciências Biológicas - ICB, Universidade Federal de Goiás - UFG, Goiânia, GO, Brazil \\ ${ }^{2}$ Faculdade de Biociências, Pontifícia Universidade Católica do Rio Grande do Sul - PUCRS, Porto Alegre, RS, Brazil \\ ${ }^{3}$ Instituto Pró-Carnívoros, Atibaia, SP, Brazil \\ ${ }^{4}$ Departamento de Zoologia, Instituto de Ciências Biológicas - ICB, Universidade de Brasília - UnB, Brasília, DF, Brazil \\ ${ }^{5}$ Departamento de Ecologia, Instituto de Biologia - IB, Universidade Federal do Rio de Janeiro - UFRJ, Rio de Janeiro, RJ, Brazil
}

\begin{abstract}
Mammals are being severely impacted by human activities and currently suffer from population declines and extinctions, loss of phylogenetic and functional diversity, and erosion of genetic diversity. Under this scenario, complementary approaches to minimize the loss of diversity are of paramount importance. Here we present how methods to identify threats, population viability, genetic diversity, and reserve selection could be integrated to improve the effectiveness of mammal conservation strategies both today and in the future. We discuss how this integration can fill current gaps in our scientific knowledge aiming at the development of more comprehensive conservation strategies for mammals. Lastly, we envisage that networks of scientific collaboration are obviously needed, so scientists from different but complementary fields could foster discussions and integrate their views and approaches. This would ultimately allow science, management and policy-making to advance together.
\end{abstract}

Key words: Biodiversity, Conservation Genetics, Extinction Risk, Habitat Loss, Population Viability Analysis, Systematic Conservation Planning.

\section{Introduction}

Most mammalian species are strongly impacted by human disturbances to natural ecosystems, and thus suffer from erosion of genetic diversity, population declines and extinctions (Schipper et al. 2008). They are also affected by loss of phylogenetic and functional diversity (sensu Euler 2001; Petchey \& Gaston 2006). The IUCN Red List of Threatened Species depicts a grim conservation status for the mammals on Earth, with one quarter of the species being threatened with extinction (see Schipper et al. 2008). Given the complexity of ecological, evolutionary, and humandriven processes acting at different spatial and temporal scales, complementary approaches to minimize the loss of mammal biodiversity are critical (Carvalho et al. 2010).

Mammals compose a diversified group that play key roles in ecosystems and provide important benefits to humans (Schipper et al. 2008). The group includes several

\footnotetext{
*Send correspondence to: Rafael Dias Loyola Departamento de Ecologia, Instituto de Ciências Biológicas, Universidade Federal de Goiás - UFG, CP 131, CEP 74001-970, Goiânia, GO, Brasil E-mail: avispa@gmail.com
}

major conservation icons, such as the tiger, and many other umbrella, keystone, indicator, and flagship species (Gittleman et al. 2001; Valenzuela-Galván \& Vázquez 2008). Their regional extinction could produce marked alterations in community composition and structure, as part of more general defaunation, which affects mesopredators, omnivores, and herbivores (Dirzo \& Miranda 1991). Some species, such as the jaguar (Panthera onca) in South America, also figure prominently in human-wildlife conflicts. This species may prey upon livestock, which, in turn, leads to human illegal activities (hunting, poaching, poisoning) that adversely affect their viability (Rondinini \& Boitani 2007; Loyola et al. 2009).

The purpose of our brief report is to highlight major themes of applied conservation research pointing to recent advances in conservation science for mammals and suggest that the way forward it to develop innovative integrated approaches to solve both academic and practical issues informing decision makers about how to apply finite funds to mammal conservation where they will be most effective (sensu Margules \& Pressey 2000; Sarkar \& Illoldi-Rangel 2010). 


\section{Major Themes in Applied Conservation Research}

\section{Applications of molecular tools for addressing conservation issues}

The application of molecular tools can illuminate a range of biological problems, several of which are important for conservation (Frankham et al. 2002). These topics include the estimation of demographic variables such as census size and dispersal patterns, improved assessments of geographic distributions and habitat requirements, along with direct analyses of genetic variation (and changes therein caused by inbreeding and habitat fragmentation), and identification of historical demographic units such as 'Evolutionarily Significant Units' (ESUs) and 'Management Units' (MUs) (Frankham et al. 2002; Eizirik et al. 2006).

Conservation genetics has recently achieved two important advances: an increasing number of models incorporating landscape complexity and life-history diversity; and the ongoing development of sophisticated methods for analysing genetic data (Ouborg 2010). High resolution markers (e.g. microsatellite, SNPs) have been applied to empirical studies of threatened populations, but extracting information on past demography and population genetic processes on the basis of marker patterns is still a challenge fostering the development of new techniques (Ouborg 2010). As a response, Bayesian clustering techniques are now frequently used along with coalescence theory, maximum likelihood approaches and Markov Chain techniques.

Still, there is a need to further integrate conservation genetics with population viability analysis (PVA), systematic conservation planning, and landscape and functional ecology. Spatial conservation prioritization, for example, has been rarely supported by assessments of local and regional genetic diversity (but see Diniz-Filho \& Telles 2006). Different disciplines capable of dealing with ecological and evolutionary processes at different levels of the biological hierarchy must interact to improve conservation strategies (Diniz-Filho et al. 2008).

\section{Population viability analysis as valuable tool for conservation}

The extinction of a species is the endpoint of a series of local population extinctions, making population losses a finer indicator of biodiversity loss (Becker \& Loyola 2008). As populations differ among themselves, studying extinction at the population level, we may record the loss of infra-specific biodiversity, such as the loss of alleles, morphological characteristics, and behaviors. If our objective is not only to conserve species, but rather conserve them along with all their infra-specific biodiversity, we need to include PVAs into conservation planning schemes (Brito \& Grelle 2006; Brito 2009).
Evolutionary approaches (such as the delimitation of ESUs and MUs, see Eizirik et al. 2006) coupled with conservation planning and PVAs might be a useful framework to identify and better preserve biodiversity (Ballou 2006). For example, genetic and molecular tools help identify important populations within an evolutionary context - they tell us which the important populations are. Conservation planning identifies spatial priorities for species conservation, indicating where the important populations are. Coupled with these two approaches PVAs are of fundamental importance because they indicate temporal persistence, i.e. they indicate which populations need conservation actions, providing a framework to guide conservation strategies to recover declining populations. At the end, we could address crucial question such as what is the impact of threats and what management actions would hold the best cost-efficiency ratios. Integrating such approaches at different scales should improve our ability to better preserve mammal biodiversity beyond the species level.

\section{Rethinking ways to establish species conservation priorities over time}

Prioritizing species by their perceived level of endangerment has become a standard practice in Conservation Biology (Mace et al. 2007). Among different methods for doing so are the rule-based ones, developed by the IUCN - which use a set of five quantitative rules with explicit thresholds to assign a risk of extinction. These methods are completely explicit about what feature of the species led to its being listed as threatened. IUCN assessors, for example, have to list the criteria whereby the species qualified for a particular category of threat, and also have to provide documentation to support this information (Mace et al. 2007).

However, such an approach only evaluates what has already taken place to put the species in danger, not considering what might happen to the species in a foreseeable future. For example, one species can be considered 'critically endangered' if, over the past 10 years or three generations, it has lost more than $90 \%$ of its population. Ideally, scientists should be able to predict what will happen with a particular species in the future in order to take conservation actions before it is too late or too difficult to reverse the extinction process.

Predictive models of habitat loss and species distribution could provide key information to estimate future extinction risk and thus contribute to determining priority areas for conservation action (Jenkins et al. 2010). For example, we could use several different modeling techniques and climatic models (Diniz-Filho et al. 2009) to predict species distribution and then assess if range shifts are likely to qualify the species for a given threat category. Uncertainty associated with these models could be quantified and mapped (Diniz-Filho et al. 2009) and used in conservation planning to indicate conservation risk of investment. Further, using available information of historical habitat fragmentation and current impacts to ecosystems (e.g. trends in agriculture and 
cattle ranching expansion, road implementation), Markov Chain models could be applied to derive future spatially explicit models of habitat loss (see Tattoni et al. 2011). These models could be than coupled to species distribution models to 'correct' possible biases in potential distributions and be evaluated under current IUCN thresholds to assign species extinction risk. This would build a proactive risk assessment in which species that might be assigned to a threat category in the future could receive immediate attention in the present.

\section{New approaches for studying landscape connectivity and population persistence}

The deficit of research on population persistence in conservation planning is likely due to lack of data and uncertainty associated with available information. Thus, landscape connectivity has been used as a proxy to guarantee population persistence in the mid-term. Reestablishing connectivity among forest remnants, for instance, has been a central theme both in Conservation Biology and Landscape Ecology (Anderson \& Jenkins 2006; Nicholson \& Ovaskainen 2009).

Recently, integrative approaches based on graphs and complex networks theories have been proposed in the context of forest fragmentation and conservation planning (Visconti \& Elkin 2009; Kininmonth et al. 2011). In graph theory, a system could be studied if there are links between nodes and every node is reachable from some other node (this would build a graph), otherwise an unconnected graph may consist of several subgraphs. The graph approach may represent real landscapes with spatially explicit elements built with geographic information system tools. Then, several graph and complex network metrics (e.g. connectance, number of connections per node, distance among nodes, node betweenness centrality) could be included in systematic conservation plans to indicate landscape elements that are crucial for the persistence of populations in space and time. These elements would be, for example, those more connected to others (a hub), or spatially close to forest remnants (Visconti \& Elkin 2009) guaranteeing gene flow and a metapopulation structure.

\section{Planning for the conservation of different aspects of biodiversity}

Because it is intuitively easily graspable and simple to measure, species richness has been the most frequent diversity metric applied in systematic conservation planning; phylogenetic diversity (which takes into account species relatedness), and functional diversity (which considers species similarities in their functional traits) are usually ignored (Safi et al. 2011). These different levels of variability are thought to be related and to determine the resulting complexity of biological interactions producing patterns of productivity, nutrient cycling, and energy flow within ecosystems (Díaz \& Cabido 2001). An integration of these aspects in conservation planning is compelling and would provide clues to understand if they are interchangeable or if they reflect different processes linked to biodiversity, so that they should be considered independently in systematic conservation plans (see Carvalho et al. 2010 for an initial approach).

Some studies have demonstrated that phylogenetic and functional diversity might be lost faster than we lose species (e.g. Heard \& Mooers 2000). Thus, preserving these different aspects of biodiversity poses a new challenge for Conservation Biology, which has not been addressed yet (but see Carvalho et al. 2010; Devictor et al. 2010), although it would be possible for mammals given the availability of data on life-history traits and large-scale phylogenies for this group. These aspects of biodiversity have been included in spatial conservation prioritization before (e.g. Loyola et al. 2008), but so far no study has evaluated whether (and how) planning for different aspects of biodiversity affect the selection of sites for conservation investment. This is a key point yet to be investigated. Another one is the real relationship between phylogenetic diversity $v s$. evolutionary processes, and functional diversity $v s$. ecosystems processes. Once these relationships are clarified, establishing conservation goals and targets based on different diversity aspects should provide a brighter picture of their intrinsic importance for both for Academia and decision makers.

\section{Future Directions}

Much progress has been made under these themes, but there are still gaps in our scientific knowledge that need to be filled if we want to develop more comprehensive conservation strategies for mammals. One of the most difficult tasks is to integrate theory and scientists working in each of these fields. Networks of scientific collaboration are obviously needed. The Brazilian Government, for example, has approved a budget of $c a$. U\$33 million for establishing national science networks for the study of biodiversity, including a network totally dedicated to the molecular identification of biodiversity. This is a first step towards such integration and further large-scale governmental investments will be critical for improving the overall quality of scientific knowledge on these topics.

Another difficult task is to effectively communicate scientific knowledge to stakeholders and decision makers to produce science-based conservation policies. Currently, we use several advanced computational tools (reflecting high technology and the complexity of analyses) that allow a more realistic understanding of biodiversity, but there is a huge time lag between scientific advances and the update of environmental laws (which may or may not adequately incorporate such advances). This means that scientists are becoming more and more confident about their models and research results, but policy makers do not follow this 
tendency, both for inherent political reasons (Metzger et al. 2010) and because Academia is not always capable of informing them about its novel findings.

This recent symposium on mammal conservation in Brazil demonstrated the enormous advances that have recently been achieved in disparate biological fields such as molecular ecology, conservation genetics, population viability analysis, rule-based methods for species conservation, and the integration of landscape connectivity and phylogenetic and functional diversity in mammal conservation planning. It was also a very stimulating opportunity to bring together scientists from each of these fields, fostering discussion and integration of their views and approaches. As highlighted by Swaisgood et al. (2010, p. 145), "Science is advancing, rapidly. Now it is time for science, management and policy-making to advance together."

\section{Acknowledgements}

This paper arose from the symposium "Conserving mammal diversity: the need for complementary approaches at different spatial and temporal scales" held at the $5^{\text {th }}$ Brazilian Congress of Mammalogy that took place in São Pedro, SP, Brazil, on 19-23 September 2010. We thank the organizing committee for their invitation and attendants of the symposium for their inputs. Authors' research is supported by $\mathrm{CNPq}$ and CAPES, Brazil.

\section{References}

Anderson $\mathrm{AB}$ \& Jenkins CN, 2006. Applying nature's design: corridors as a strategy for biodiversity conservation. New York: Columbia University Press.

Ballou JD, 2006. Population viability analysis and conservation planning. In: Morato RG et al., (eds.). Manejo e conservação de carnívoros neotropicais: I workshop de pesquisa para a conservação. São Paulo: IBAMA. p. 85-96.

Becker CG \& Loyola RD, 2008. Extinction risk assessments at the population and species level: Implications for amphibian conservation. Biodiversity and Conservation, 17:2297-2304. http://dx.doi.org/10.1007/s10531-007-9298-8

Brito D \& Grelle CEV, 2006. Estimating minimum area of suitable habitat and viable population size for the northern muriqui (Brachyteles hypoxanthus). Biodiversity and Conservation, 15:4197-4210. http://dx.doi.org/10.1007/s10531-005-3575-1

Brito D, 2009. Population viability analysis: a tool for biodiversity conservation in Brazil. Oecologia Brasiliensis, 13:450-467.

Carvalho RA et al., 2010. Drafting a Blueprint for Functional and Phylogenetic Diversity Conservation in the Brazilian Cerrado. Natureza \& Conservação, 8:171-176.

Devictor V et al., 2010. Spatial mismatch and congruence between taxonomic, phylogenetic and functional diversity: the need for integrative conservation strategies in a changing world. Ecology Letters, 13:1030-1040.

Díaz S \& Cabido M, 2001. Vive la différence: plant functional diversity matters to ecosystem processes. Trends Ecology and Evolution, 16:646-655. http://dx.doi.org/10.1016/ S0169-5347(01)02283-2

Diniz-Filho JAF \& Telles MPC, 2006. Optimization procedures for establishing reserve networks for biodiversity conservation taking into account population genetic structure. Genetics and Molecular Biology, 29:207-214. http://dx.doi.org/10.1590/ S1415-47572006000200004

Diniz-Filho JAF et al., 2008. Mapping the evolutionary twilight zone: molecular markers, populations and geography. Journal of Biogeography, 35:753-763. http://dx.doi. org/10.1111/j.1365-2699.2008.01912.x

Diniz-Filho JAF et al., 2009. Partitioning and mapping uncertainties in ensembles of forecasts of species turnover under climate change. Ecography, 32:897-906. http://dx.doi. org/10.1111/j.1600-0587.2009.06196.x

Dirzo R \& Miranda A, 1991. Altered patterns of herbivory and diversity in the forest understory: a case study of the possible consequences of contemporary defaunation. In: Price $\mathrm{P}$ et al., (eds.). Plant-animal interactions: Evolutionary ecology in tropical and temperate regions. New York: John Wiley \& Sons Inc. p. 273-287.

Eizirik E, Johnson WE \& O'Brien SJ, 2006. Definindo unidades evolutivamente significativas e unidades de manejo para a conservação de carnívoros neotropicais. In: Morato RG et al., (eds.). Manejo e conservação de carnívoros neotropicais: I workshop de pesquisa para a conservação. São Paulo: IBAMA. p. 47-63.

Frankham R, Ballou JD \& Briscoe DA, 2002. Introduction to conservation genetics. Cambridge: Cambridge University Press.

Gittleman JL et al., 2001. Carnivore Conservation. Cambridge: Cambridge University Press.

Heard SB \& Mooers AÒ, 2000. Phylogenetically patterned speciation rates and extinction risks change the loss of evolutionary history during extinctions. Proceedings of the Royal Society of London B, 267:613-620. PMid:10787167. PMCid:1690578. http://dx.doi.org/10.1098/rspb.2000.1046

Jenkins CN, Alves MAS \& Pimm SL, 2010. Avian conservation priorities in a top-ranked Biodiversity Hotspot. Biological Conservation, 143:992-998. http://dx.doi.org/10.1016/j. biocon.2010.01.014

Kininmonth S et al., 2011. Dispersal connectivity and reserve selection for marine conservation. Ecological Modelling, 222:1272-1282. http://dx.doi.org/10.1016/j. ecolmodel.2011.01.012

Loyola RD et al., 2008. Conservation of Neotropical carnivores under different prioritization scenarios: mapping species traits to minimize conservation conflicts. Diversity and Distributions, 14:949-960. http://dx.doi. org/10.1111/j.1472-4642.2008.00508.x

Loyola RD et al., 2009. Integrating Economic Costs and Biological Traits into Global Conservation Priorities for Carnivores. PLoS ONE 4(8):e6807. PMid:19710911. PMCid:2728536. http://dx.doi.org/10.1371/journal.pone.0006807

Mace G, Possingham HP \& Leader-Williams N, 2007. Prioritizing choices in conservation. In: Macdonald DW \& Service 
$\mathrm{K}$ (eds.). Key topics in conservation biology. Oxford: Blackwell. p. 17-34.

Margules CR \& Pressey RL, 2000. Systematic conservation planning. Nature, 405:243-253. PMid:10821285. http:// dx.doi.org/10.1038/35012251

Metzger JPW et al., 2010. Brazilian Law: Full Speed in Reverse? Science, 329:276-277. PMid:20647446. http://dx.doi. org/10.1126/science.329.5989.276-b

Nicholson E \& Ovaskainen O, 2009. Conservation prioritization using metapopulation models. In: Moilanen A, Wilson K \& Possingham HP (eds.). Spatial conservation prioritization: quantitative methods and computational tools. Oxford: Oxford University Press. p. 110-121.

Ouborg NJ, 2010. Integrating population genetics and conservation biology in the era of genomics. Biology Letters, 6:3-6. PMid:19726442. PMCid:2817254. http:// dx.doi.org/10.1098/rsbl.2009.0590

Petchey OL \& Gaston KJ, 2006. Functional diversity: back to basics and looking forward. Ecology Letters, 9:741-758. PMid:16706917. http://dx.doi. org/10.1111/j.1461-0248.2006.00924.x

Rondinini C \& Boitani L, 2007. Systematic Conservation Planning and the Cost of Tackling Conservation Conflicts with Large Carnivores in Italy. Conservation Biology, 21:1455-1462. PMid:18173469. http://dx.doi. org/10.1111/j.1523-1739.2007.00834.x

Safi K et al., 2011. Understanding global patterns of mammalian functional and phylogenetic diversity. Philosophical Transactions of the Royal Society B (in press).
Sarkar S \& Illoldi-Rangel P, 2010. Systematic Conservation Planning: an Updated Protocol. Natureza \& Conservação, 8:19-26.

Schipper J et al., 2008. The Status of the World's Land and Marine Mammals: Diversity, Threat, and Knowledge. Science, 322:225-230. PMid:18845749. http://dx.doi.org/10.1126/ science. 1165115

Swaisgood RR et al., 2010. Giant panda conservation science: how far we have come. Biology Letters, 6:143-145. http:// dx.doi.org/10.1098/rsbl.2009.0786

Tattoni C, Ciolli M \& Ferretti F, 2011. The fate of priority areas for conservation in protected areas: a fine-scale Markov chain approach. Environmental Management, 47:263-278. http://dx.doi.org/10.1007/s00267-010-9601-4

Valenzuela-Galván D \& Vázquez LB, 2008. Prioritizing areas for conservation of Mexican carnivores considering natural protected areas and human population density. Animal Conservation, 11:215-223. http://dx.doi. org/10.1111/j.1469-1795.2008.00171.x

Visconti P \& Elkin C, 2009. Using connectivity metrics in conservation planning - when does habitat quality matter? Diversity and Distributions, 15:602-612. http://dx.doi. org/10.1111/j.1472-4642.2009.00564.x

Euler F von, 2001. Selective extinction and rapid loss of evolutionary history in the bird fauna. Proceedings of the Royal Society of London B, 268:127-130. PMid:11209881. PMCid:1088581. http://dx.doi.org/10.1098/rspb.2000.1340

Received: April 2011

First Decision: May 2011

Accepted: May 2011 
